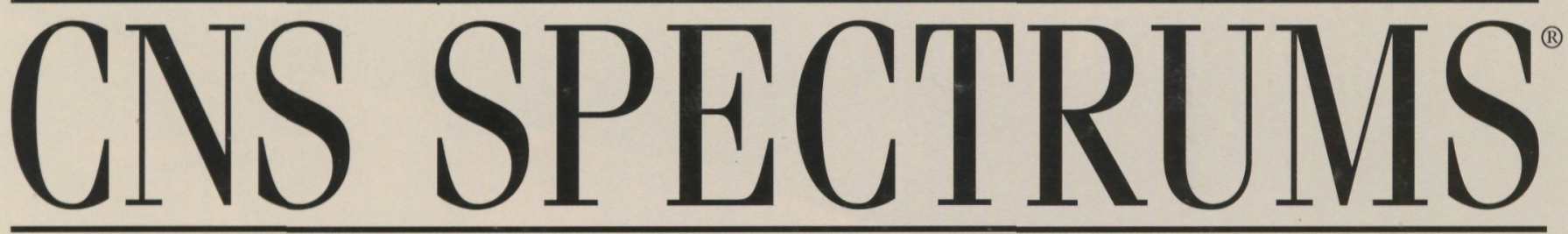

The International Journal of Neuropsychiatric Medicine

\title{
Unresolved Questions About Treatment-Resistant Anxiety Disorders
}

D.J. Stein and S. Seedat

Generalized Anxiety Disorder:

Acute and Chronic Treatment

M.A. Rynn and O. Brawman-Mintzer

Treatment-Resistant Panic Disorder

B. Bandelow and E. Rüther

Treatment-Resistant Posttraumatic Stress Disorder:

Strategies for Intervention

M.B. Hamner, S. Robert, and B.C. Frueh

Optimizing Treatment in Social Phobia:

A Review of Treatment Resistance

M. Van Ameringen, C. Mancini, B. Pipe, M. Bennett

Cognitive Deficits Following Coronary Artery Bypass Grafting:

Prevalence, Prognosis, and Therapeutic Strategies

P.V.Raja, J.A. Blumenthal, and P.M. Doraiswamy 


\section{NEW ADULT INDICATION}

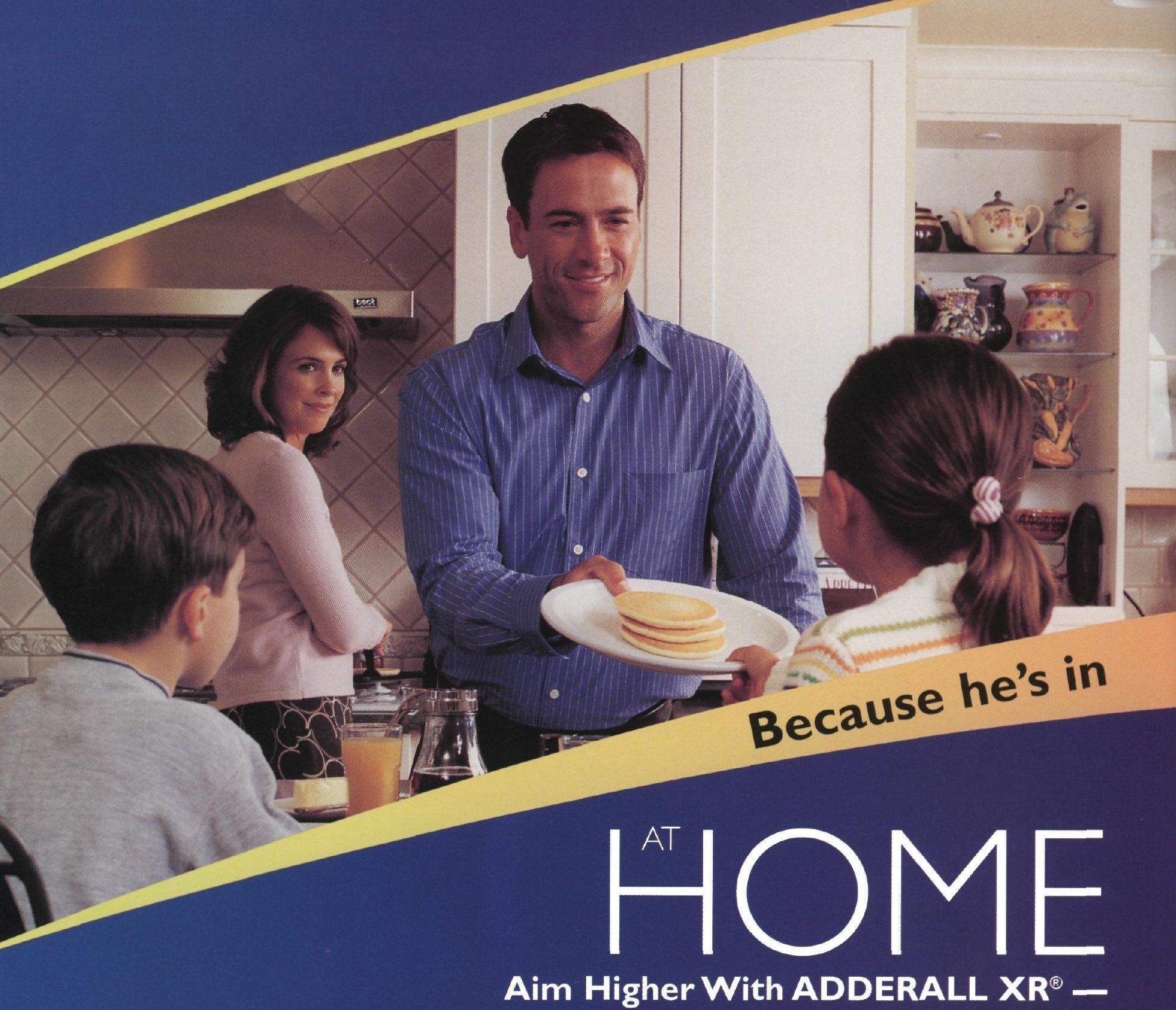

The most common adverse events in pediatric trials included loss of appetite, insomnia, abdominal pain, and emotional lability. The most common adverse events in the adult trial included dry mouth, loss of appetite, insomnia, headache, and weight loss.

The effectiveness of ADDERALL XR for long-term use has not been systematically evaluated in controlled trials. As with other psychostimulants indicated for ADHD, there is a potential for exacerbating motor and phonic tics and Tourette's syndrome. A side effect seen with the amphetamine class is psychosis. Caution also should be exercised in patients with a history of psychosis.

Abuse of amphetamines may lead to dependence. Misuse of amphetamines may cause sudden death and serious cardiovascular adverse events. ADDERALL XR generally should not be used in children or adults with structural cardiac abnormalities. ADDERALL XR is contraindicated in patients with symptomatic cardiovascular disease, moderate to severe hypertension, hyperthyroidism and glaucoma, known hypersensitivity to this class of compounds, agitated states, history of drug abuse, or current or recent use of MAO inhibitors. ADDERALL XR should be prescribed with close physician supervision. 


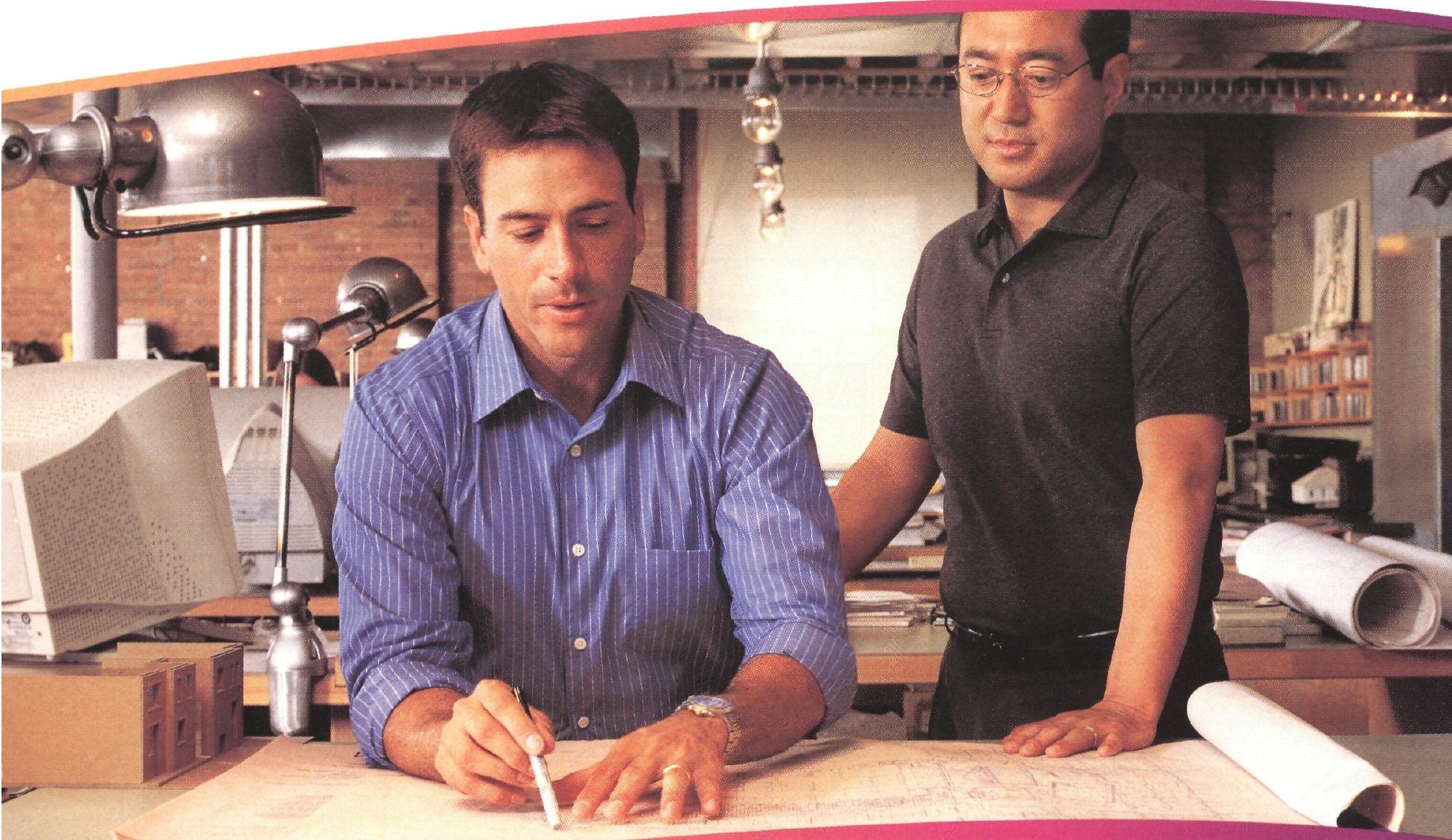

demand all day long...

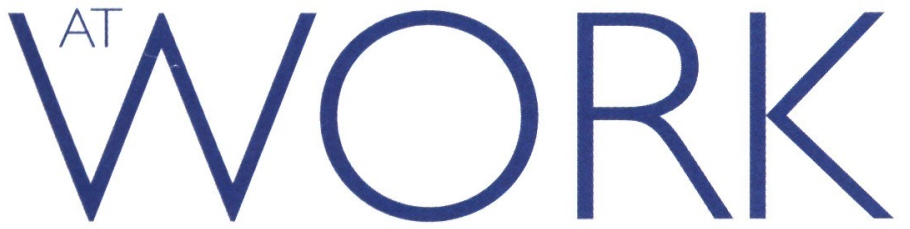

For Efficacy That Measures Up to Life's Demands

- Once-daily dosing provides all-day symptom control'

- Mean ADHD-RS total scores for adults receiving ADDERALL XR decreased by $41 \%$ '

- ADDERALL XR is the only stimulant medication approved to treat adults with ADHD'

- Clinical data in adults demonstrate that ADDERALL XR is generally well tolerated' 
BRIEF SUMMARY: Consult the full prescribing information for complete product information. ADDERALL XR` CAPSULES

CII Ax Only

AMPHETAMINES HAVE A HIGH POTENTIAL FOR ABUSE. ADMINISTRATION OF AMPHETAMINES FOR PROLONGED PERIODS OF TIME MAY LEAD TO DRUG DEPENDENCE. PARTICULAR ATTENTION SHOULD BE
PAID TO THE POSSIBILITY OF SUBJECTS OBTAINING AMPHETAMINES FOR NON-THERAPEUTIC USE OR DISTRIBUTION TO OTHERS AND THE DRUGS SHOULD BE PRESCRIBED OR DISPENSED SPARINGLY.

MISUSE OF AMPHETAMINE MAY CAUSE SUDDEN DEATH AND SERIOUS CARDIOVASCULAR ADVERSE

IMDICATIONS

ADDERALL XR is indicated for the treatment of Attention Deficit Hyperactivity Disorder (ADHD).

The efficacy of ADDERALL XR in the treatment of ADHD was established on the basis of two controlled trials in children aged 6 to 12 , and one controlled trial in adults who met DSM-IV criteria
PHARMACOLOGY), along with extrapolation from the known efficacy of ADDERALL" the

\section{CONTRAINDICATIONS}

Advanced arteriosclerosis, symptomatic cardiovascular disease, moderate to severe hypertension, hyperthyroidism, known hypersensitivity or idlosyncrasy to the sympathomimetic amines, glaucoma. Agitated states. Patients with a history of drug abuse.
During or within 14 days following the administration of monoamine oxidase inhibitors (hypertensive crises may result)

WARNINGS

Prychosis: Clinical experience suggests that, in psychotic patients, administration of amphetamine may exacerbate symptoms of behavior disturbance and thought disorder.

Long-Term Suppression of Growth: Data are inadequate to determine whether chron-

ic use of stimulants in children, including amphetamine, may be causally associated with suppression of growth. Therefore, growth should be monitored during treatment, and patients who are not growing or gaining weight as expected should have their treatment interrupted.

Sudden Death and Pre-existing Structural Cardiac Abnormalities: Sudden death has been reported in association with amphetamine treatment at usual doses in children with structural cardiac abnom
Adderall $\mathrm{XR}^{*}$ generally should not be used in children or adults with structural cardiac abnormalities.

PRECAUTIONS

General: The least amount of amphetamine feasible should be prescribed or dispensed at one time in order to minimize the possibility of overdosage.

Hypertension: Caution is to be exercised in prescribing amphetamines for patients with even mild hypertension (See CONTRAINDICATIONS). Blood pressure and pulse should be monitored at appropriate intervals in patients taking ADDERALL XR ${ }^{\otimes}$, especially patients with hypertension.

Tlcs: Amphetamines have been reported to exacerbate motor and phonic tics and Tourette's syndrome. Therefore clinical evaluation for tics and Tourette's syndrome in children and their families should precede use of stimulan medications.

Information for Patients: Amphetamines may impair the ability of the patient to engage in potentially hazardous activities such as operating machinery or vehicles; the patient should therefore be cautioned accordingly.

Drug Interaetions: Acidifying agents - Gastrointestinal acidifying agents (guanethidine, reserpine, glutamic acid $\mathrm{HCl}$, ascorbic acid etc) lower absorption of amphetamines Urinary acidffying agents-These agents ammonium chloride, sodium acid phosphate, etc.) increase the concentration of the ionized species of the amphetamine molecule, thereby increasing urinary excretion. Both groups of agents lower blood levels and efficacy of amphetamines. Adrenergic blockers-Adrenergic blockers are inhibited by amphetamines. Alkalinizing agentsGastrointestinal alkalinizing agents (sodium bicarbonate, etc.) increase absorption of amphetamines. Co-administration of ADDERALL XR and gastrointestinal alkalinizing agents, such as antacids, should be avoided. Urinary alkalinizing agents (acetazolamide, some thiazides) increase the concentration of the non-lonized species of the amphetemine molecule, thereby decreasing urinary excretion. Both groups of agents increase blood levels and
therefore potentiate the actions of amphetamines. Antidepressants, tricyclic-Amphetamines may enhance the therefore potentiate the actions of amphetamines. Antidepressants, tricyclic-Amphetamines may enhance the activity of tricyclic antidepressants or sympathomimetic agents; $d$-amphetamine with desipramine or protriptyline and possibly other tricyclics cause striking and sustained increases in the concentration of d-amphetamine in the brain; cardiovascular effects can be potentiated. MAO inhibitors-MAOl antidepressants, as well as a metabolite
of furazolidone, slow amphetamine metabolism. This slowing potentiates amphetamines, Increasing their effect on the release of norepinephrine and other monoamines from adrenergic nerve endings; this can cause headaches and other signs of hypertensive crisis. A variety of toxic neurological effects and malignant hyperpyrexia can occur, sometimes with fatal results. Antihistamines-Amphetamines may counteract the sedative effect of antihistamines. Antihypertensives-Amphetamines may antagonize the hypotensive effects of antihypertensives Chlorpromazino-Chlorpromazine blocks doparnine and norepinephrine receptors, thus inhibiting the central stimulant effects of amphetamines, and can be used to treat amphetamine poisoning. EthosuximideAmphetamines may delay intestinal absorption of ethosuximide. Haloperidol-Haloperidol blocks dopamine receptors, thus inhibiting the central stimulant effects of amphetamines. Lithium carbonate- The anorectic and stimulatory effects of amphetamines may be inhibited by lithium carbonate. Meperidine-Amphetamines potentiate the analgesic effect of meperidine. Methenamine therapy-U -Urinary excretion of amphetamines is increased and efficacy is reduced, by aciditying agents used in methenamine therapy. Norepinephrine-Amphetamines enhance the adrenergic effect of norepinephrine. Phenobarbita-Amphetamines may delay intestinal absorption of phenobarbital; co-administration of phenobarbital may produce a synergistic anticonvulsant action. PhenytoinAmphetamines may delay intestinal absorption of phenytoin; co-administration of phenytoin may produce a synergistic anticonvulsant action. Propoxyphene- in cases of propoxyphene overdosage, ampheta-
mine CNS stimulation is potentiated and fatal convulsions can occur. Veratrum alkaloids-Amphetamines inhibit the hypotensive effect of veratrum alkaloids.

Drughaboratory Test Interactions: Amphetamines can cause a significant elevation in plasma corticosteroid

levels. This increase is greatest in the evening. Amphetamines may interfere with urinary steroid determinations, Carcinogenesis/Mutagenesis and Impairment of Fentility: No evidence of carcinogenicity was found in studies in which d,1-amphetamine (enantiomer ratio of 1:1) was administered to mice and rats in the diet for 2 years a doses of up to $30 \mathrm{mg} / \mathrm{kg} / \mathrm{day}$ in male mice, $19 \mathrm{mg} / \mathrm{kg} / \mathrm{day}$ in female mice, and $5 \mathrm{mg} / \mathrm{kg} / \mathrm{day}$ in male and female
rats. These doses are approximately $2.4,1.5$, and 0.8 times, respectively, the maximum recommended human rats. These doses are approximately $2.4,1.5$, and 0.8 times, respect
dose of $30 \mathrm{mg} /$ day [child] on a $\mathrm{mg} / \mathrm{m}^{2}$ body surface area basis.

dose of $30 \mathrm{mg} / \mathrm{day}$ [child] on a mg/m² body surface area basis. Amphetamine, in the enantiomer ratio present in ADDERALL (immediate-release)(d- to 1 - ratio of $3: 1$ ), was not clastogenic in the mouse bone marrow micronucleus test in vivo and was negative when tested in the $E$. coll component of the Ames test in vitro. d, l-Amphetamine (1:1 enantiomer ratio) has been reported to produce a
positive response in the mouse bone marrow micronucleus test, an equivocal response in the Ames test, and negative responses in the in vitro sister chromatid exchange and chromosomal aberration assays.

Amphetamine, in the enantiomer ratio present in ADDERALL ${ }^{*}$ (immediate-release) (d- to I- ratio of 3:1), did not adversely affect fertllity or early embryonic development in the rat at doses of up to $20 \mathrm{mg} / \mathrm{kg} / \mathrm{day}$ (approximately

Pregnancy: Pregnancy Category C. Amphetamine, in the enantiomer ratio present in ADDERALL ${ }^{\infty}$ (d- to 1 - ratio of 3:1), had no apparent effects on embryofetal morphological development or survival when orally administered to respectively. These doses are approximately 1.5 and 8 times, respectively, the maximum recommended human dose of $30 \mathrm{mg} /$ day [child] on a $\mathrm{mg} / \mathrm{m}^{2}$ body surface area basis. Fetal malformations and death have been reported in mice following parenteral administration of d-amphetamine doses of $50 \mathrm{mg} / \mathrm{kg} / \mathrm{day}$ (approximately 6 times that of a human dose of $30 \mathrm{mg} / \mathrm{day}$ [child] on a mg/m $\mathrm{m}^{2}$ basis) of
Administration of these doses was also associated with severe maternal toxicity.

A number of studies in rodents indicate that prenatal or early postnatal exposure to amphetamine (d- or $d-1$ ) A number of studies in rodents indicate that prenatal or early postnatal exposure to amphetamine ( $d-$ or $d, 1-$, a doses similar to those used clinically, can result in long-term neurochemical and behavioral alterations. Reporter There are no adequate and well-controlled studies in pregnant women. There has been one report of severe congenital bony deformity, tracheo-esophageal fistula, and anal atsesia (vater association) in a baby born to a woman who took dextroamphetamine sulfate with lovastatin during the first trimester of pregnancy. Nonteratogenic Effects: Infants born to mothers dependent on amphetamines have an increased risk of Nonteratogenic Efiects: Infants born to mothers dependent on amphetamines have an increased risk of
premature delivery and low birth weight. Also, these infants may experience symptoms of withdrawal as
demonstrated by dysphoria, including agitation, and significant lassitude.

Usage in Mursing Mothers: Amphetamines are excreted in human milk. Mothers taking amphetamines should be

Pediatric Use: ADDERALL XR ${ }^{\oplus}$ is indicated for use in children 6 years of age and olde

Use in Children Under SIX Years of Age: Effects of ADDERALL XR in 3-5 year olds have not been studied. Long-term effects of amphetamines in children have not been well established. Amphetamines are not Gerlatric Use: ADDERALL XR has not been studied in the gariatric population. ADVERSE EVENTS

The premarketing development program for ADDERALL XR included exposures in a total of 965 participants in clinical trials (635 pediatric patients, 248 adult patients, 82 healthy adult subjects). Of these, 635 patients (age 6 to 12) were evaluated in two controlled clinical studies, one open-label clinical study, and two single-dose clin-
ical pharmacology studies ( $\mathrm{N}=40$ ). Safety data on all patients are included in the discussion that follows. Adverse reactions were assessed by collecting adverse events, results of physical examinations, vital signs, weights, laboratory analyses, and ECGs.

Adverse events during exposure were obtained primarily by general inquiry and recorded by clinical investigators using terminology of their own choosing. Consequently, it is not possible to provide a meaningful estimate of the proportio of individuals experiencing adverse events without first grouping similar types of events into a smaller number of standardized event categoie

The stated frequencies of adverse events represent the proportion of individuals who experienced, at least once, The stated frequencies of adverse events represent the
treatment-emergent adverse event of the type listed.

Adverse events associated with discontinuation of treatment: In two placebo-controlled studies of up to 5 weeks duration among children with ADHD, 2.4\% (10/425) of ADDERALL XR treated patients discontinued due to adverse events (including 3 patients with loss of appetite, one of whom also reported insomnia) compared to $2.7 \%$ (7/259) receiving placebo. The most frequent adverse events associated with discontinuation of ADDERALL XR ${ }^{3}$ in

controlled and uncontrolled, multiple-dose clinical trials of pediatric patients ( $N=595$ ) are presented below.
of these patients were exposed to ADDERALL XF for 12 months or more.
Adverse event

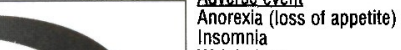

$$
\begin{array}{lr}
\text { Anorexia (loss of appetite) } & 2.9 \\
\text { Insomnia } & 1.5 \\
\text { Weight loss } & 1.2 \\
\text { Emotional lability } & 1.0 \\
\hline
\end{array}
$$

\section{A I LY}

(II)

In one placebo-controlled 4-week study among adults with $A D H D$, patients who discontinued treatment due to adverse events among ADDERALL XR A $^{-1 r e a t e d ~ p a t i e n t s ~}$ $(n=5)$ for insomnia, $1 \%(n=2)$ each for headache, palpitation, and somnolence; and $0.5 \%(n=1)$ each for ALI increase, agitation, chest pain, cocaine craving, elevated blood pressure, and weight loss.

Adverse events occurring in a controlled trial: Adverse events reported in a 3-week clinical trial of pediatric patients and a 4-week clinical trial in adults treated with ADDERALL XR or placebo are in the tables below.

The prescriber should be aware that these figures cannot be used to predict the incidence of adverse events in the course of usual medical practice where patient characteristics and other factors differ from those which prevailed investigations inolving different treatme clinica prescribing physician with some basis for estimating the relative contribution of drug and non-drug factors to the prescribing physician with some basis for estimating the

Table 1 Adverse Events Reported by More Than $1 \%$ of Pediatric Patients Receiving ADDERALL XR* with

\begin{tabular}{|c|c|c|c|}
\hline Body System & Preferred Term & ADDERALL XR $\mathrm{X}^{\circ}(\mathrm{n}=374)$ & Placebo $(n=210)$ \\
\hline General & $\begin{array}{l}\text { Abdominal Pain (stomachache) } \\
\text { Accidental Injury } \\
\text { Asthenia (fatigue) } \\
\text { Fever } \\
\text { Iffection } \\
\text { Viral Infection }\end{array}$ & $\begin{array}{l}14 \% \\
3 \% \\
2 \% \\
5 \% \\
4 \% \\
2 \% \\
4 \% \\
\end{array}$ & $\begin{array}{l}10 \% \\
2 \% \\
0 \% \\
2 \% \\
2 \% \\
0 \% \\
\end{array}$ \\
\hline $\begin{array}{l}\text { Digestive } \\
\text { System }\end{array}$ & $\begin{array}{l}\text { Loss of Appetite } \\
\text { Diarrhea } \\
\text { Dyspepsia } \\
\text { Nausea } \\
\text { Vomiting } \\
\end{array}$ & $\begin{array}{l}22 \% \\
2 \% \\
2 \% \\
5 \% \\
7 \% \\
\end{array}$ & $\begin{array}{l}2 \% \\
1 \% \\
1 \% \\
3 \% \\
4 \% \\
\end{array}$ \\
\hline Nervous System & $\begin{array}{l}\text { Dizziness } \\
\text { Emotional Liability } \\
\text { Insomnia } \\
\text { Nerwousness } \\
\end{array}$ & $\begin{array}{c}2 \% \\
9 \% \\
17 \% \\
6 \% \\
\end{array}$ & $\begin{array}{l}0 \% \\
2 \% \\
2 \% \\
2 \% \\
\end{array}$ \\
\hline Metabolic/Nutritlona! & Weight Loss & $4 \%$ & $0 \%$ \\
\hline
\end{tabular}
Higher Ineidence Than on Placebo in a 584 Patient Clinical Study

Table 2 Adverse Events Reported by $5 \%$ or More of Adults Receiving ADDERALL XR ${ }^{\circ}$ with HIgher Ineidence

\begin{tabular}{|c|c|c|c|}
\hline Body System & Preferred Term & ADDERALL XR ${ }^{\oplus}(n=191)$ & Placebo $(n=64)$ \\
\hline General & $\begin{array}{l}\text { Asthenia } \\
\text { Headache }\end{array}$ & $\begin{array}{l}6 \% \\
26 \% \\
\end{array}$ & $\begin{array}{l}5 \% \\
13 \% \\
\end{array}$ \\
\hline Digestlve System & $\begin{array}{l}\text { Loss of Appetite } \\
\text { Diarrnea } \\
\text { Dry Mouth } \\
\text { Nausea }\end{array}$ & $\begin{array}{l}33 \% \\
6 \% \% \\
35 \% \\
8 \% \\
\end{array}$ & $\begin{array}{l}3 \% \\
0 \% \\
5 \% \\
3 \%\end{array}$ \\
\hline Nervous System & $\begin{array}{l}\text { Agitation } \\
\text { Anxiety } \\
\text { Dizziness } \\
\text { Insomnia }\end{array}$ & $\begin{array}{l}8 \% \\
8 \% \% \\
7 \% \\
27 \%\end{array}$ & $\begin{array}{l}5 \% \\
5 \% \\
0 \% \\
13 \%\end{array}$ \\
\hline Cardiovascular System & Tachycardia & $6 \%$ & $3 \%$ \\
\hline Metabolic/Nutrlitional & Weight Loss & $11 \%$ & $0 \%$ \\
\hline Urogenltal System & Urinary Tract Infection & $5 \%$ & $0 \%$ \\
\hline
\end{tabular}
Than on Placebo in a 255 Patient clinical Forced Weakly-Dose Titration Study*

Note: The following events did not meet the criterion for inclusion in Table 2 but were reported by $2 \%$ to $4 \%$ of adult patients receiving ADDERALL XR ${ }^{\circ}$ with a higher incidence than patients receiving placebo in this study: infection, photosensitivity reaction, constipation, tooth disorder, emotional lability,

*included doses up to $60 \mathrm{mg}$

The following adverse reactions have been associated with amphetamine use: Cardiovascular: Palpitations, tachycardia, elevation of biood pressure, sudden death, myocardial infarction. There have been isolated reports of cardiomyopathy associated with chronic amphetamine use. Central Nervous System: Psychotic episodes at recommended doses, overstimulation, restlessness, dizziness, insomnia, euphoria, dyskinesia, dysphoria, depression, tremor, headache, exacerbation of motor and phonic tics and Tourette's syndrome, seizures, stroke. Gastrointestinal: Dryness of the mouth, unpleasant taste, diarrhea, constipation, other gastrointestinal disturbances. Ano
weight loss may occur as undesirable effects. Allergic: Urticaria. Endocrine: Impotence, changes in libido.

DRUG ABUSE AND DEPENDENCE

ADDERALL XR is a Schedule II controlied substance

Amphetamines have been extensively abused. Tolerance, extreme psychological dependence, and severe social disability have occurred. There are reports of patients who have increased the dosage to many times that recommended. Abrupt cessation following prolonged high dosage administration results in extreme fatigue and mental depression; changes are also noted on the sleep EEG. Manifestations of chronic intoxication with changes. The most severe manifestation of chronic intoxication is psychosis, often clinically indistinguishable from schizophrenia.

OVERDOSAGE

individual patient response to amphetamines varies widely. Toxic symptoms may occur idiosyncratically at low doses. Symptoms: Manifestations of acute overdosage with amphetamines include restlessness, tremor, hyperreflexia, rapid respiration, confusion, assaultiveness, hallucinations, panic states, hyperpyrexia and rhabdomyolysis. Fatigue and depression usually follow the central nervous system stimulation. Cardiovascular effects include vomiting, diarrhea, and abdominal cramps. Fatal poisoning is usually preceded by convulsions and coma. Treatment: Consult with a Certified Poison Control Center for up to date guidance and advice. Management of acute amphetamine intoxication is largely symptomatic and includes gestr administration of a cathartic and sedation. Experience with hemodialysis or peritoneal dialysis is inadequate to permit recommendation in this regard. Acidification of the urine increases amphetamine excretion, but is believed to. increase risk of acute renal failure if myoglobinuria is present. If acute severe hypertension complicates amphetamine overdosage, administration of intravenous phentolamine has been suggested. However, a gradual drop in blood stimulant effects of amphetamines and can be used to treat amphetamine intoxication.

The prolonged release of mixed amphetamine salts from ADDERALL XR ${ }^{*}$ should be considered when treating patients with overdose

Dispense in a tight, light-resistant container as defined in the USP. Store at $25^{\circ} \mathrm{C}\left(77^{\circ} \mathrm{F}\right)$. Excursions permitted to $15-30^{\circ} \mathrm{C}\left(59-86^{\circ} \mathrm{F}\right)$ [see USP Controlled Room Temperature]

Manufactured for: Shire US Inc., Newport, KY 41071 Made in USA For more information call 1-800-828-2088, or visit www. adderall xr.com. ADDER

403980

3810107004

Rev. 9/04

Shire 


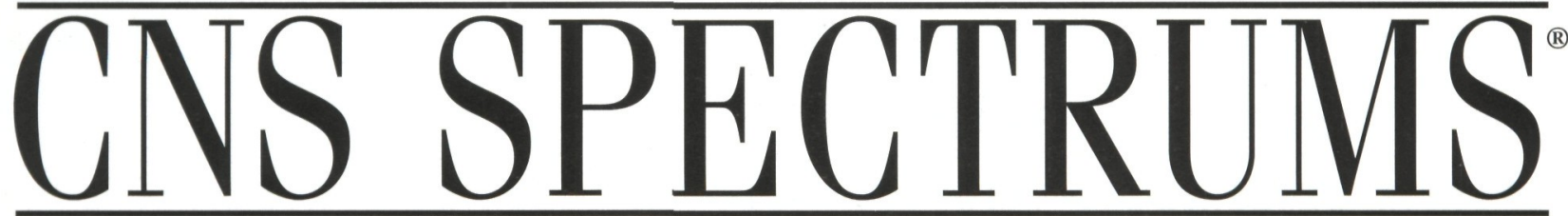

\section{The International Journal of Neuropsychiatric Medicine}

\section{EDITOR}

Jack M. Gorman, MD

Mount Sinai School of Medicine

New York, NY

ASSOCIATE AND FOUNDING EDITOR
Eric Hollander, MD
Mount Sinai School of Medicine
New York, NY
INTERNATIONAL EDITOR
Joseph Zohar, MD
Chaim Sheba Medical Center
Tel-Hashomer, Israel

ASSOCIATE INTERNATIONAL EDITORS EUROPE

Donatella Marazziti, MD

University of Pisa

Pisa, Italy

\section{MID-ATLANTIC}

Dan J. Stein, MD, PhD

University of Stellenbosch

Tygerberg, South Africa

\section{FAR EAST}

Shigeto Yamawaki, MD, PhD

Hiroshima University School

of Medicine

Hiroshima, Japan

CONTRIBUTING WRITERS

Borwin Bandelow, MD, PhD

Mark B. Hamner, MD

Pushpa V. Raja, BA

Moira A. Rynn, MD

Dan J. Stein, MD, PhD

Soraya Seedat, MB ChB, FC Psych (SA)

Michael Van Ameringen, MD, FRCPC

MEDICAL REVIEWER

David L. Ginsberg, MD

\section{BOARD OF ADVISORS \\ NEUROLOGISTS}

Mitchell F. Brin, MD

University of California, Irvine Irvine, CA

Jeffrey L. Cummings, MD

University of California, Los Angeles Los Angeles, CA

Jerome Engel, Jr., MD, PhD

University of California, Los Angeles

Los Angeles, CA

Mark S. George, MD

Medical University of South Carolina

Charleston, SC

Deborah Hirtz, MD

National Institute of Neurologica

Disorders and Stroke, NIH

Rockville, MD

Richard B. Lipton, MD

Albert Einstein College of Medicine Bronx, NY

C. Warren Olanow, MD, FRCPC

Mount Sinai School of Medicine New York, NY

Steven George Pavlakis, MD

Maimonides Medical Center

Brooklyn, NY

Stephen D. Silberstein, MD, FACP

Thomas Jefferson University

Philadelphia, PA

Michael Trimble, MD, FRCP, FRPsych National Hospital for Neurology and Neurosurgery

London, United Kingdom

\section{PSYCHIATRISTS}

Margaret Altemus, MD

Cornell University Medical College New York, NY

Dennis S. Charney, MD

National Institute of Mental Health

Bethesda, MD

Dwight L. Evans, MD

University of Pennsylvania

Philadelphia, PA

Siegfried Kasper, MD

University of Vienna

Vienna, Austria

Martin B. Keller, MD

Brown Medical School

Providence, RI
Lorrin M. Koran, MD

Stanford University School of Medicine Stanford, CA

Yves Lecrubier, MD

Hôpital de la Salpêtrière

Paris, France

Herbert Y. Meltzer, MD

Vanderbilt University Medical Center Nashville, TN

Stuart A. Montgomery, MD

St. Mary's Hospital Medical School

London, United Kingdom

Charles B. Nemeroff, MD, PhD

Emory University School of Medicine

Atlanta, GA

Humberto Nicolini, MD, PhD

National Mexican Institute of Psychiatry

Mexico City, Mexico

Stefano Pallanti, MD, PhD

University of Florence

Florence, Italy

Katharine Phillips, MD

Brown Medical School

Providence, RI

Harold A. Pincus, MD

Western Psychiatric Institute \& Clinic

RAND-University of Pittsburgh Health

Institute, Pittsburgh, PA

Scott L. Rauch, MD

Massachusetts General Hospital

Charlestown, MA

Alan F. Schatzberg, MD

Stanford University School of Medicine

Stanford, CA

Thomas E. Schlaepfer, MD

University of Bonn

Bonn, Germany

Stephen M. Stahl, MD, PhD

University of California, San Diego La Jolla, CA

Norman Sussman, MD, DFAPA

New York University Medical School New York, NY

Karen Dineen Wagner, MD, PhD

The University of Texas Medical Branch Galveston, Texas

Herman G.M. Westenberg, MD

University Hospital Utrecht

Utrecht, The Netherlands

Stuart C. Yudofsky, MD

Baylor College of Medicine

Houston, TX
MBL COMMUNICATIONS Corporate Staff

CEO \& PUBLISHER

Darren L. Brodeur

ASSOCIATE PUBLISHER

Elizabeth Katz

MANAGING EDITOR

Christopher Naccari

SENIOR EDITOR

Deborah Hughes

DEPUTY SENIOR EDITOR

José R. Ralat

ACQUISITIONS EDITORS

Lisa Arrington

Shoshana Bauminger
ASSISTANT EDITOR

Emil J. Ross

COPY EDITOR

Keith Papa

PUBLISHING ASSOCIATE

Shelley Wong

ART DIRECTOR

Derek Oscarson

CONTROLLER

John Spano

NATIONAL ACCOUNT MANAGER

Kathleen J. Skae, MBA

\section{INFORMATION TECHNOLOGY}

Clint Bagwell Consulting

OFFICE ASSISTANT

Manuel Pavón

CORPORATION COUNSEL

Lawrence Ross, Esq.

Bressler, Amery, and Ross 


\section{The Anxiety Disorders}

\section{Association of America}

announces its

\section{Awards Program Call for Applications}

Available online at www.adaa.org

\section{CAREER DEVELOPMENT TRAVEL AWARD - \$3,500}

Deadline: Tuesday, November 30, 2004

\section{JUNIOR FACULTY RESEARCH GRANT - \$30,000} Deadline: Tuesday, December 9, 2004

TRAINEE TRAVEL AWARD - \$1,500 Deadline: Monday, December 20, 2004

Fifteen awardees are selected to attend the ADAA's 25th Annual Conference, March 17-20, 2005, in Seattle, Washington. To date, the ADAA Awards Program has given more than 75 travel awards and 15 research grants, totaling nearly $\$ 700,000$.

For award descriptions, eligibility requirements, award criteria, and applications, please visit the ADAA Web site at www.adaa.org. For more information, contact the ADAA Awards program manager, Jane Caroline Parham, at (P) 240-485-1016, (F) 240-485-1035, or email at jparham@adaa.org.

\section{About the ADAA}

The ADAA is the only national, nonprofit partnership of researchers, health care professionals, and individuals dedicated solely to the early diagnosis, prevention, and treatment of anxiety disorders. It is the Association's goal to promote professional and public awareness and understanding of anxiety disorders. It also seeks to increase the availability of effective treatment, reduce the stigma surrounding anxiety disorders, and stimulate research. 


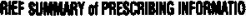

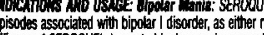

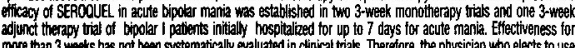

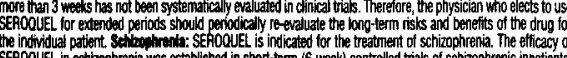

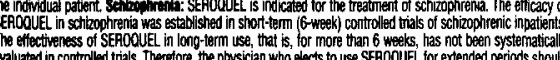

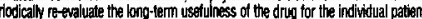

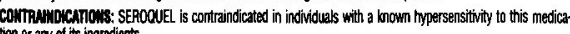

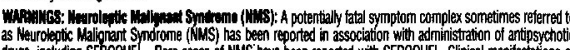

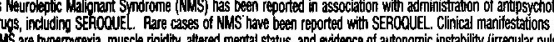

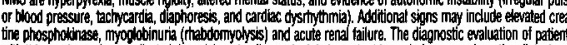

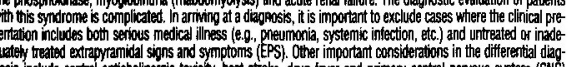

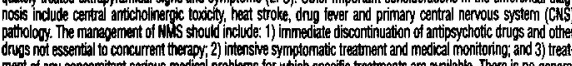

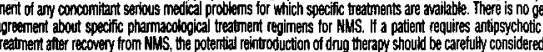

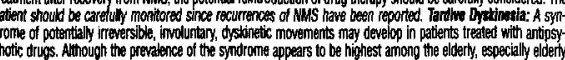

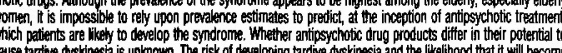

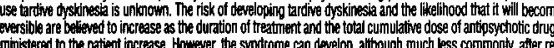

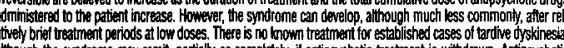

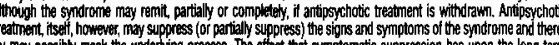

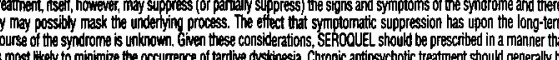

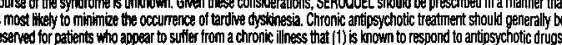

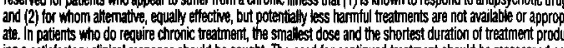

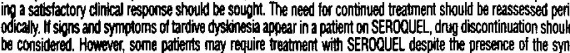

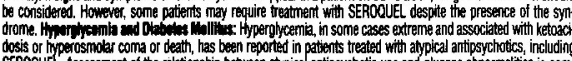

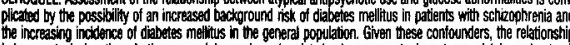

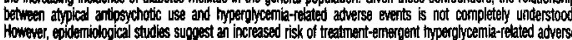

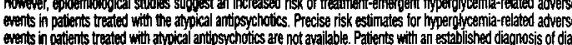

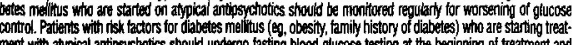

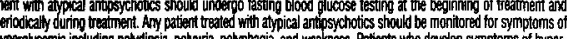

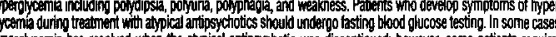

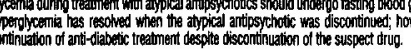

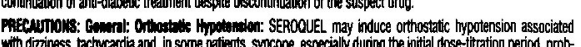

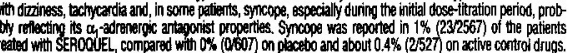

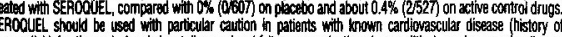

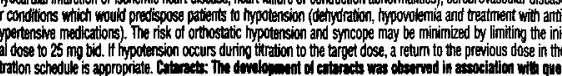

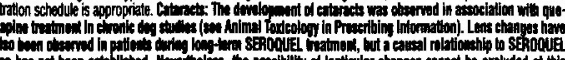

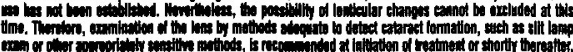

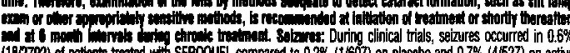

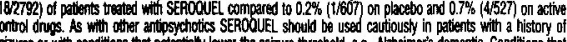

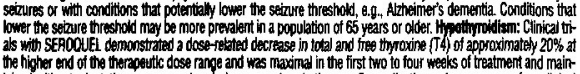

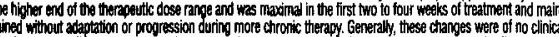

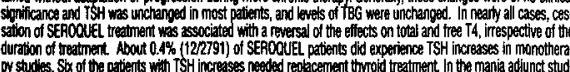

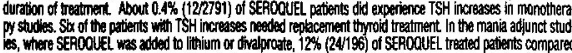

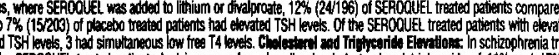

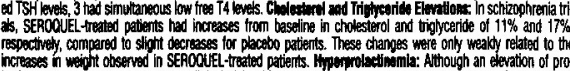

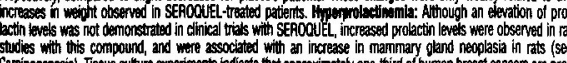

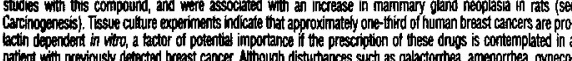

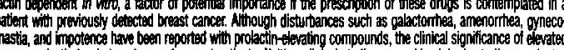

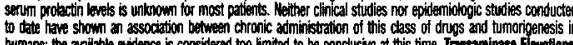

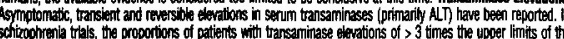

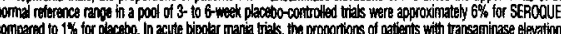

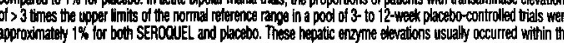

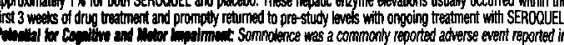

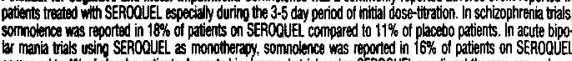

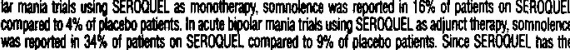

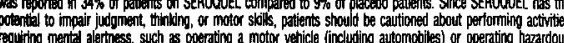

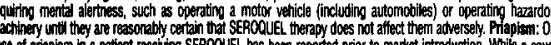

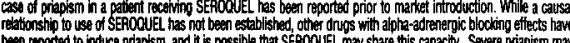

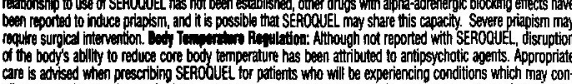

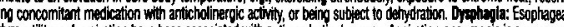

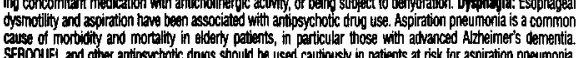

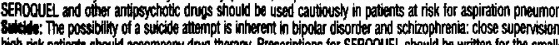

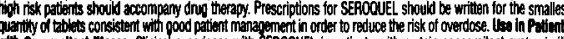

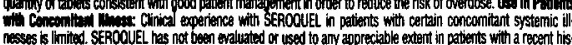

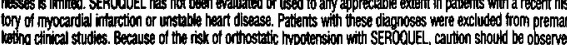

SEROQUEL ${ }^{\circledR}$ (quetiapine fumarate) Tablets

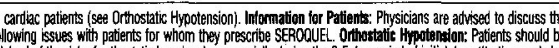

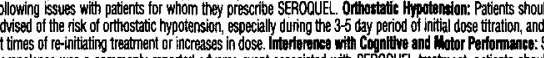

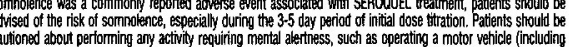

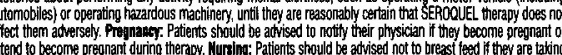

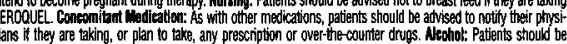

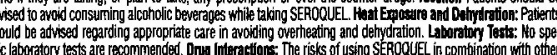

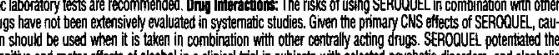

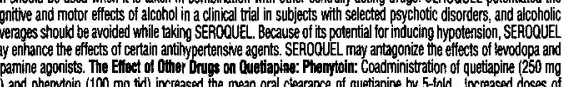

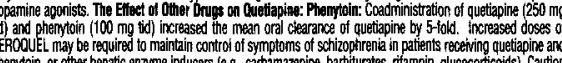

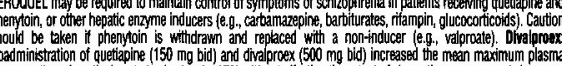

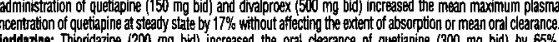

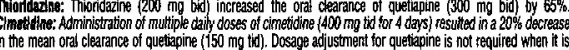

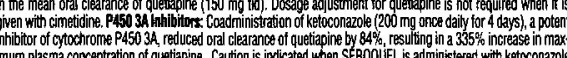

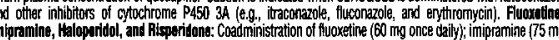

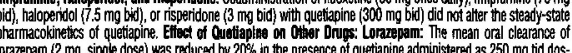

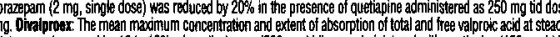

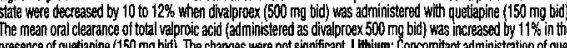

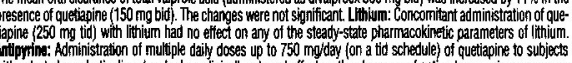

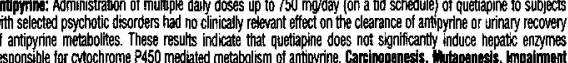

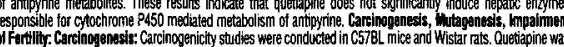

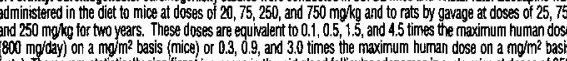

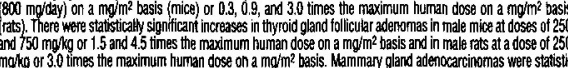

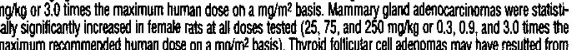

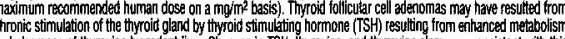

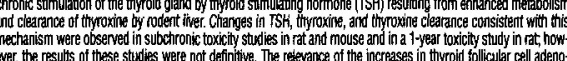

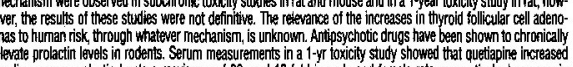

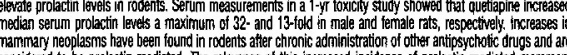

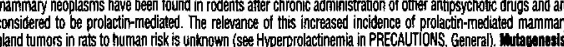

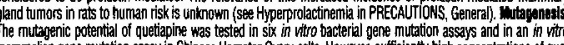

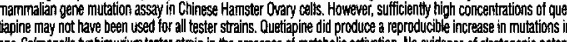

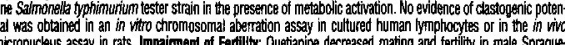

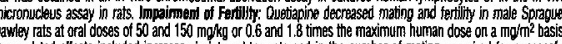
Orug-realteded effects included increases in interval to mate and in the number of matings reguirsed for successfiu

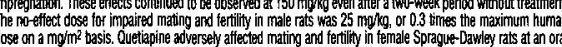

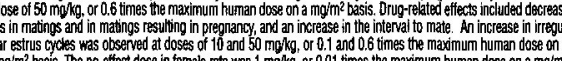

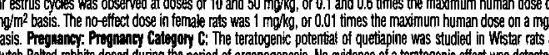

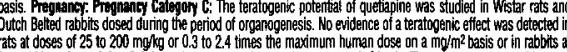

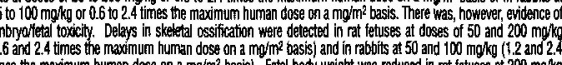

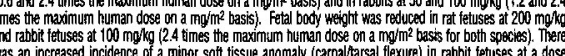

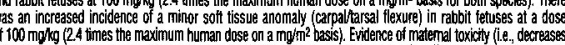

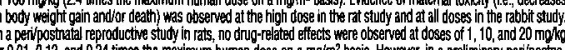

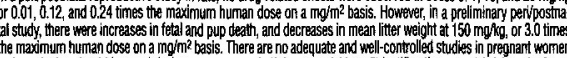

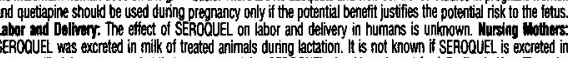

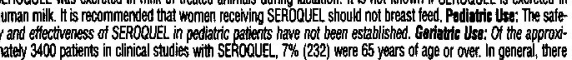

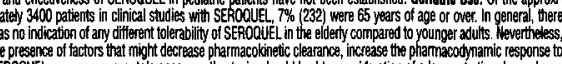

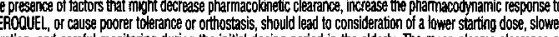

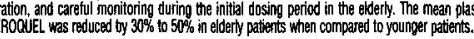

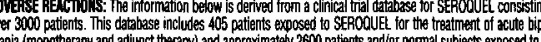

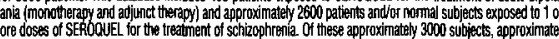

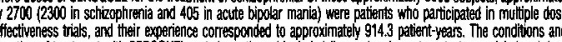

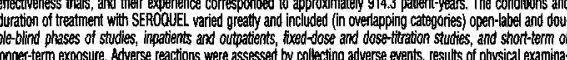

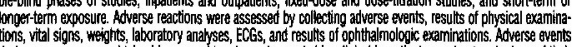

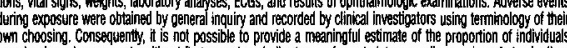

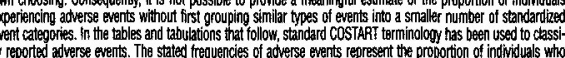

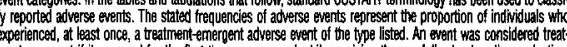

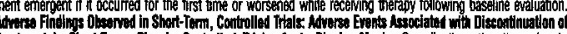

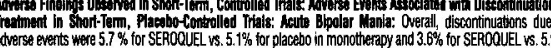

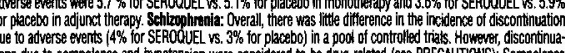

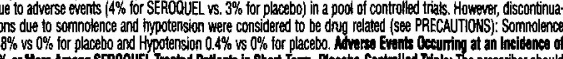

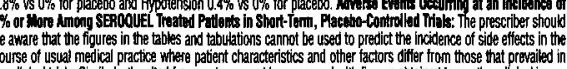

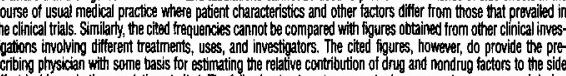

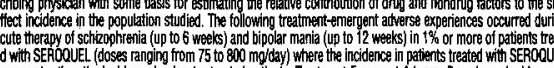

SEROOUEL 8 (quetiapine fumarate) Jablets

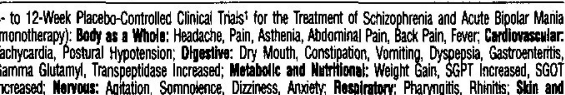

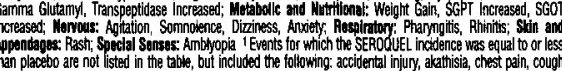

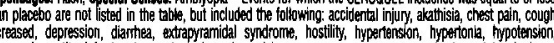

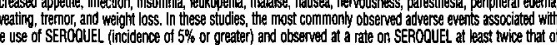

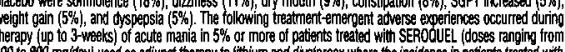

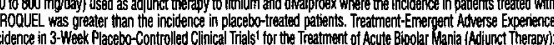

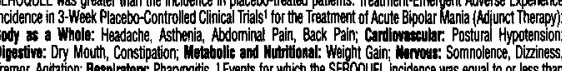

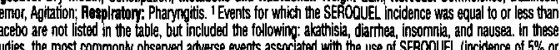

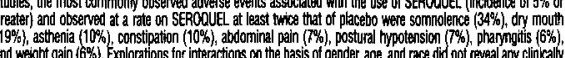

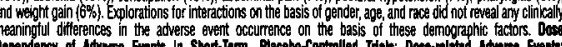

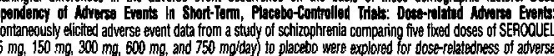

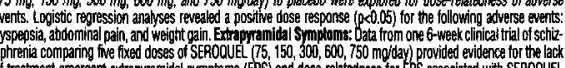

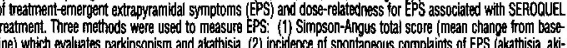

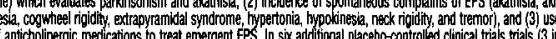

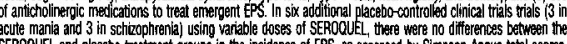

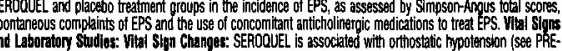

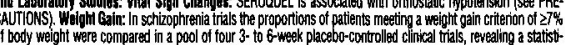

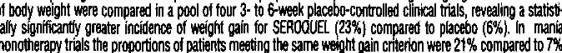

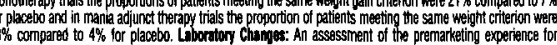

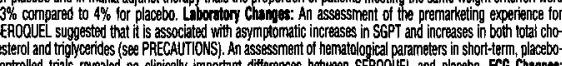

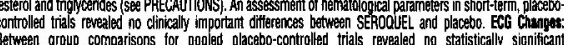

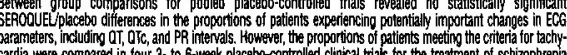

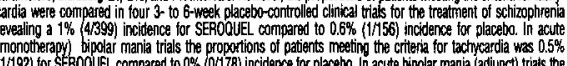

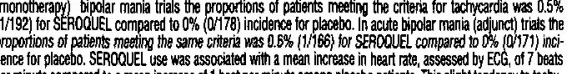

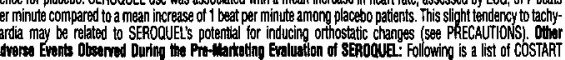

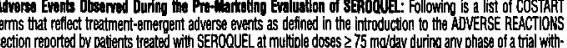

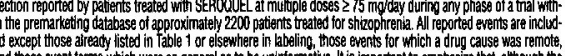

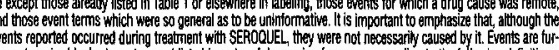

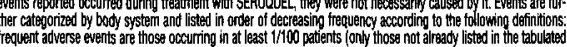

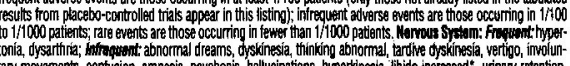

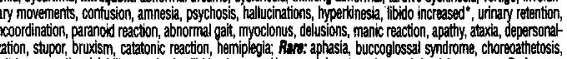

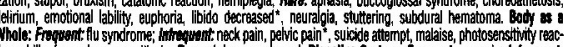

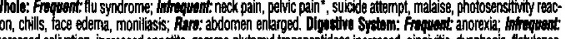

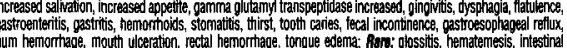

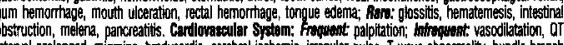

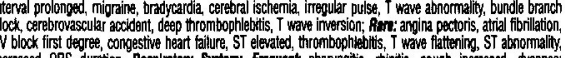

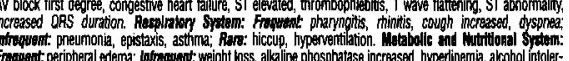

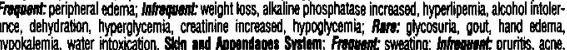

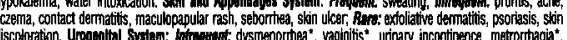

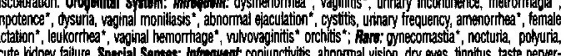

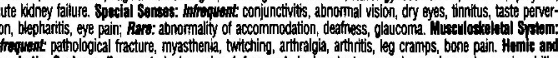

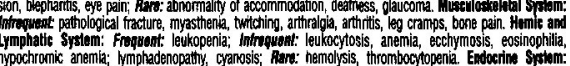

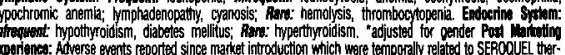

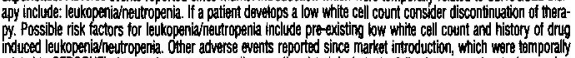

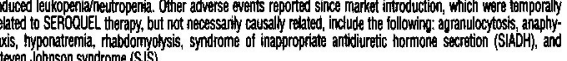

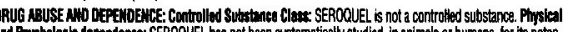

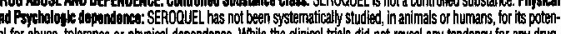

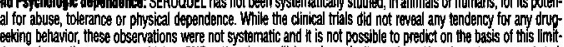

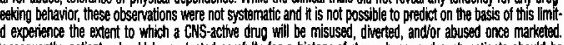

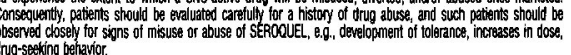

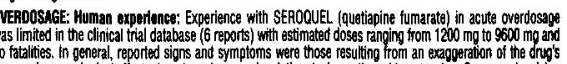

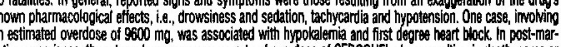

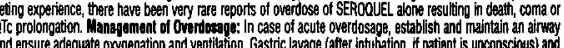

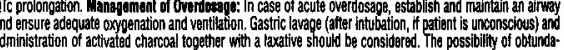

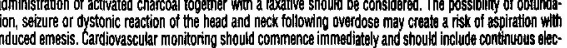

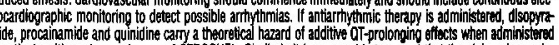

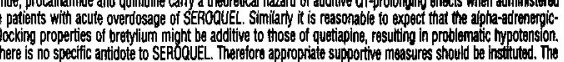

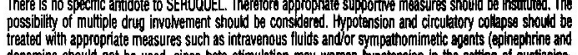

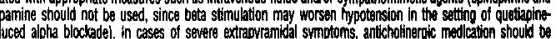

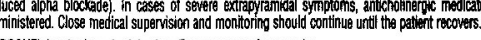




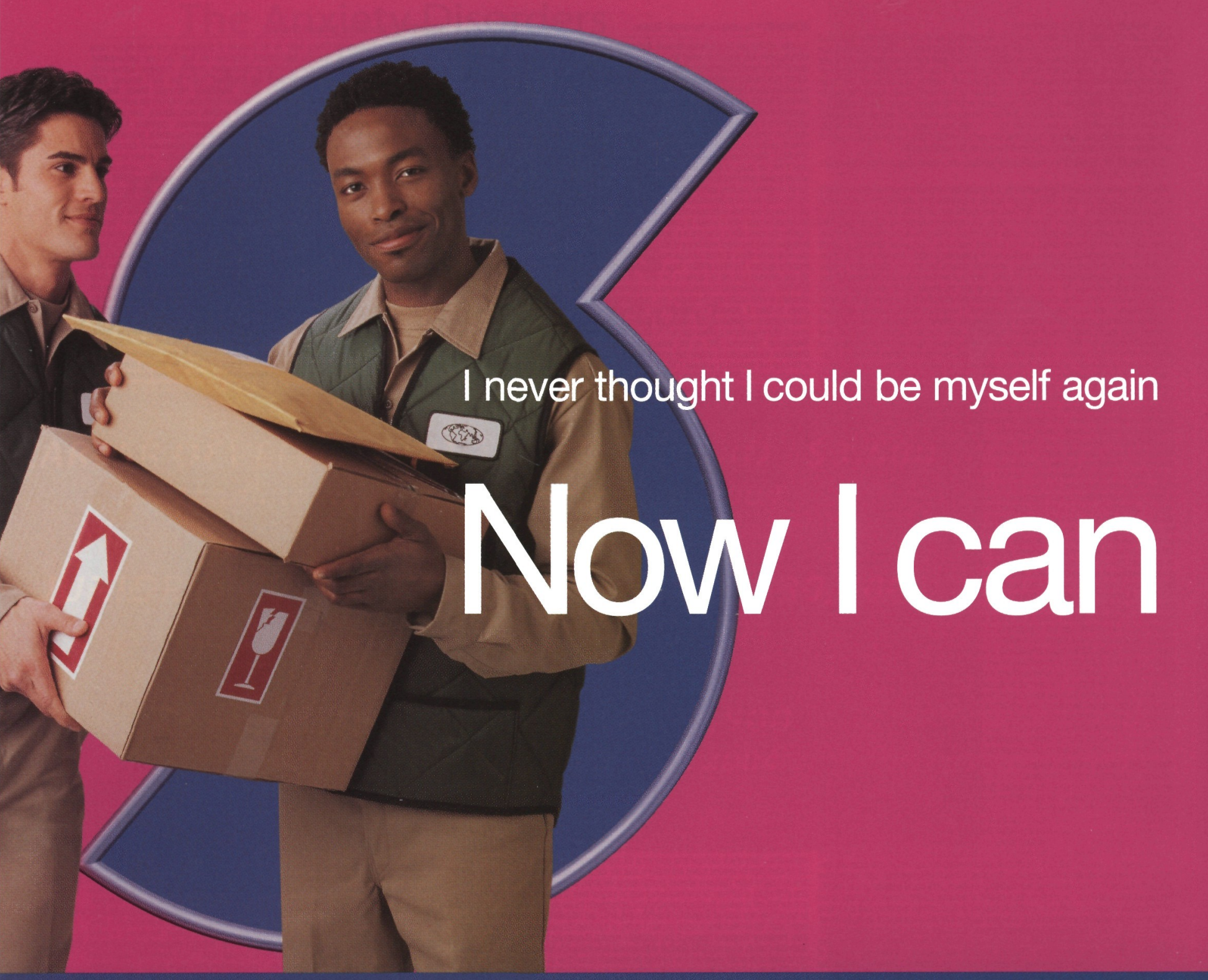

SEROQUEL is indicated for the treatment of acute manic episodes associated with bipolar I disorder and the treatment of schizophrenia. Patients should be periodically reassessed to determine the need for continued treatment.

Prescribing should be consistent with the need to minimize the risk of tardive dyskinesia, seizures, and orthostatic hypotension. A rare condition referred to as neuroleptic malignant syndrome (NMS) has been reported with this class of medications, including SEROQUEL.

There have been reports of diabetes mellitus and hyperglycemia-related adverse events associated with the use of atypical antipsychotics, including SEROQUEL.

The most commonly observed adverse events associated with the use of SEROQUEL in clinical trials were somnolence, dry mouth, dizziness, constipation, asthenia, abdominal pain, postural hypotension, pharyngitis, SGPT increase, dyspepsia, and weight gain.

\section{AstraZeneca}

AstraZeneca Pharmaceuticals LP

To prevent medication errors, write "SEROQUEL" clearly on your Rx pad. Spell "SEROQUEL" clearly over the phone.

(c) 2004 AstraZeneca Pharmaceuticals LP. All rights reserved. SEROQUEL is a registered trademark of the AstraZeneca group of companies.

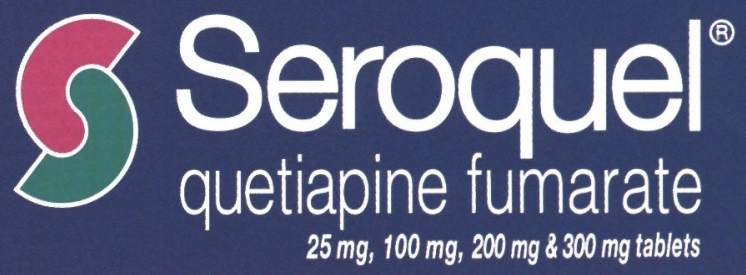

\section{Redefine Success}

WWW.SEROQUEL.com 


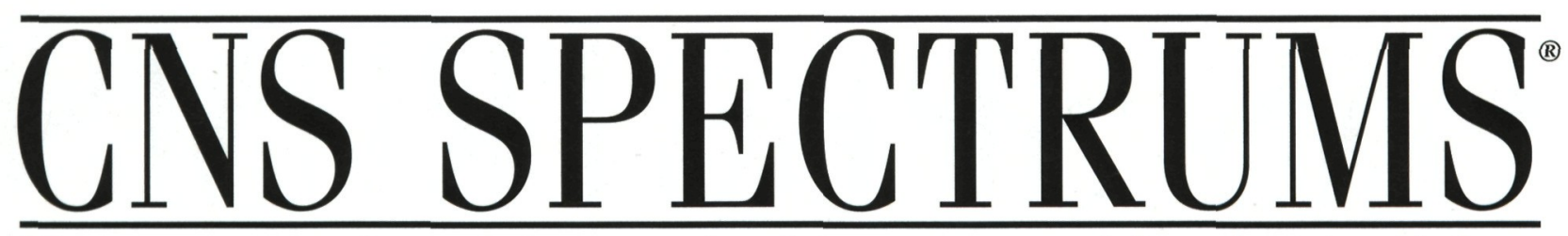

The International Journal of Neuropsychiatric Medicine

\section{Table of Contents}

715 Introduction: Unresolved Questions About Treatment-Resistant Anxiety Disorders Dan J. Stein, MD, PhD, University of Stellenbosch; and Soraya Seedat, MB ChB, FC Psych (SA), University of Stellenbosch

716 Generalized Anxiety Disorder: Acute and Chronic Treatment Moira A. Rynn, MD, University of Pennsylvania; and Olga Brawman-Mintzer, MD, Medical University of South Carolina

725 Treatment-Resistant Panic Disorder Borwin Bandelow, MD, PhD, University of Göttingen; and Eckart Rüther, MD, University of Göttingen

740 Treatment-Resistant Posttraumatic Stress Disorder: Strategies for Intervention

Mark B. Hamner, MD, Medical University of South Carolina; Sophie Rober, PharmD, Medical University of South Carolina; and B. Christopher Frueh, PhD, Medical University of South Carolina

753 Optimizing Treatment in Social Phobia:

A Review of Treatment Resistance

Michael Van Ameringen, MD, FRCPC, McMaster University Medical Centre;

Catherine Mancini, MD, FRCPC, McMaster University Medical Centre;

Beth Pipe, BScN, BEd, McMaster University Medical Centre;

and Mark Bennett, BA, McMaster University Medical Centre

763 Cognitive Deficits Following Coronary Artery Bypass Grafting:

Prevalence, Prognosis, and Therapeutic Strategies

Pushpa V. Raja, BA, Johns Hopkins School of Medicine;

James A. Blumenthal, PhD, Duke University Medical Center;

and P. Murali Doraiswamy, MD, Duke University Medical Center 


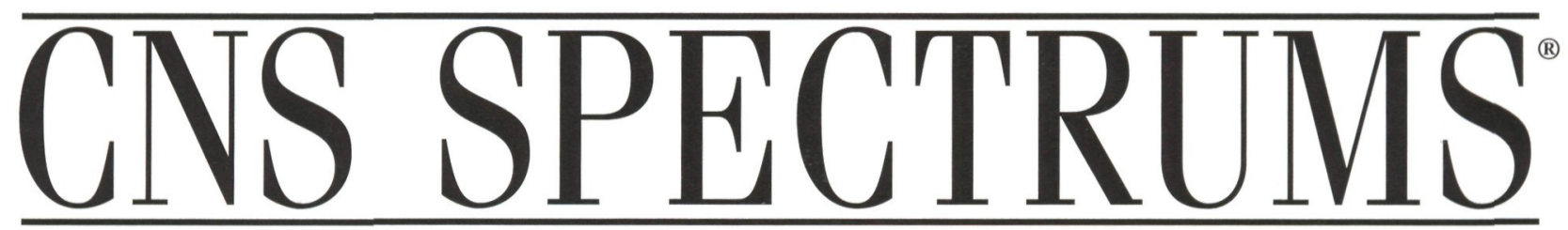

The International Journal of Neuropsychiatric Medicine

\section{Table of Contents}

\section{Departments/Monthly Columns}

\section{EROM THE EDITOR'S DESK}

708 Easing the Burden: Treating Refractory Anxiety By Jack M. Gorman, MD

\section{CLINICAL UPDATES IN NEUROPSYCHIATRY}

709 Breaking News From the Field of Neuroscience

- FDA Approves Two-Drug Combination for the Treatment of Parkinson's Disease

- Atypical Neuroleptics May Be Helpful in

Treatment-Resistant Depression

- Duloxetine May Be Effective in Treating Fibromyalgia

- Galantamine Hydrobromide Found to Have No Benefit in Chronic Fatigue Syndrome

- International Survey Reveals Attention-Deficit/Hyperactivity Disorder Diagnosis Takes an Average of Two Years

- Prospective Study Finds Association Between Multiple Sclerosis and the Hepatitis $B$ Vaccine

\section{CME QUIZ}

776 The quiz on treatment-resistant anxiety disorders is CME-accredited by Mount Sinai School of Medicine for 3.0 credit hours.

\section{ACADEMIC SUPPLEMENT}

Are All Atypical Antipsychotics Equal for the Treatment of Cognition and Affect in Schizophrenia?

Stephen M. Stahl, MD, PhD,

Herbert Y. Meltzer, MD, Jonathan M. Meyer, MD, and Lili C. Kopala, MD, FRCPC
Founded in 1996, CNS Spectrums is an Index Medicus journal and is available on MEDLINE under the citation CNS Spectr. It is available online at www.cnsspectrums.com.

CNS Spectrums (ISSN 1092-8529) is published monthly by MBL Communications, Inc. 333 Hudson Street, 7th Floor, New York, NY 10013.

One-year subscription rates: domestic $\$ 120$; foreign $\$ 185$; in-training $\$ 75$. For subscriptions: Phone: 212-328-0800; Fax: 212-328-0600; Web: www.cnsspectrums.com.

Postmaster: Send address changes to CNS Spectrums c/o PPS Medical Marketing Group 264 Passaic Avenue, Fairfield, NJ 07004-2595.

For editorial inquiries, please fax us at 212-3280600 or e-mail us at jrr@mblcommunications. com. For bulk reprint purchases, please contact: Kathleen J. Skae at ks@mblcommunications.com.

Opinions and views expressed by authors are their own and do not necessarily reflect the views of the publisher, MBL Communications, Inc., or the editorial advisory board. Advertisements in CNS Spectrums are accepted on the basis of adherence to ethical medical standards, but acceptance does not imply endorsement by CNS Spectrums or the publisher.

CNS Spectrums is a registered trademark of CNS Spectrums, LLC, New York, NY. Permission to reproduce articles in whole or part must be obtained in writing from the publisher.

BPA Worldwide Membership Applied for August 2004. Audit Bureau of Circulations member.

Copyright (C)2004 by MBL Communications, Inc. All rights reserved. Printed in the United States. 


\section{(H)}

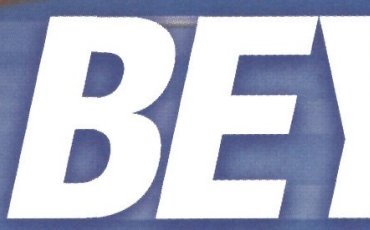

10

THE

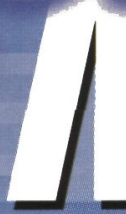

Introducing NEW $25 \mathrm{mg}$ and $50 \mathrm{mg}$ capsules of ZONEGRAN ${ }^{\odot}$ (zonisamide)

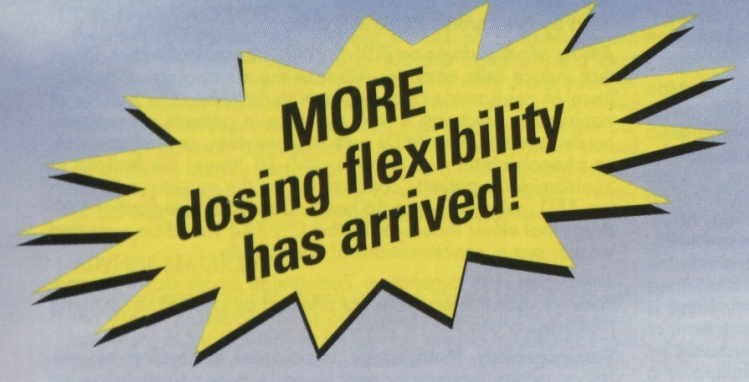

ZONEGRAN is indicated as adjunctive therapy in the treatment of partial seizures in adults with epilepsy.

In clinical trials, the most common adverse events that occurred with ZONEGRAN were somnolence, dizziness, anorexia, headache, nausea, and agitation/irritability.

*Can also be dosed twice daily.

Please see brief summary of Prescribing Information on adjacent page.

References: 1. ZONEGRAN" Prescribing Information. Elan Pharmaceuticals. 2002. 2. Brodie M, Wilson E, Smith D, et al. Steady-state drug interaction study of zonisamide and lamotrigine in
epileptic patients. Neurology. 2001;56(3):A337 (abstract). 3. Data on file. Elan Pharmaceuticals, Inc.

\footnotetext{
Distributed by Elan Biopharmaceuticals, a business unit of Elan Pharmaceuticals, Inc
(EPI), a member of the Elan Group. ZONEGRAN and the Z are trademarks of, or

More dosing options for meeting patients' needs

- Increase your dosing flexibility

- Choose from 3 dosage strengths:

$25 \mathrm{mg}, 50 \mathrm{mg}$, and $100 \mathrm{mg}$ capsules

-Tailor therapy to the individual patient

\section{Proven efficacy with} confidence-building benefits ${ }^{1-3}$

- Few drug-to-drug interactions

- Minimal cognitive impairment

-63-hour half-life-the longest of any newer AED

- Convenient QD dosing ${ }^{*}$

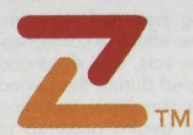

\section{zonegran}

zonisamide capsules 
CONTRAINDICATONS

ZONEGRAN is contraindicated in patients who have demonstrated hypersensitivity to sulfonamides or zonisamide. WARNINGS

Potentially Fotal Reactions to Sulfonamides: Fatalities have occurred, although rarely, as a resulf of severe reactions vens-Johnson syndrome, toxic epidermal necrolysis, fulminant hepatic necrosis, agranulocytosis, aplastic anemia, and other blood dyscrasias. Such reactions may occur when a sultor tion. If signs of hypersensitivity or other serious reactions occur hon. If signs of hyparsensingsporive of the route of administra sulfonamidetype adverse reaction to zonisamide is described

Serious Skin Reactions: Consideration should be given to discontinuing ZONEGRAN in potients who develop an otherwis unexplained rash. If the drug is not discontinued, patients rash [i.e. Stevens-Johnson syndrome (SJS) and toxic epidermo necrolysis (TEN)] were reported in the first 11 years of market ing in Japan. All of the patients were receiving other drugs in addition to zonisomide. In post-marketing experience from in addition to zonan, a total of 49 cases of SJS or TEN have been reported, a reporting rate of 46 per million patientyears of exposure.
Although this rate is greater than background, it is probably an Although this rate is greater than background, it is probably an underestimate of the true incidence because of Under-report-
ing. There were no confirmed cases of SJS or TEN in the US, programs.

In the US and European randomized controlled trials, 6 of 269 (2.2\%) zonisamide patientsdiscontinued treatment because of rash compared to none on placebo. Across all trials during the ation of zonisamide was reported in $1.4 \%$ of patients 112.0 events per 1000 patient-years of exposure). During Japanese development, serious rash or rash that led to study drug discontinuation was reported in $2.0 \%$ of patients 127.8 events pe with $85 \%$ reported within 16 weeks in the US and Eurooean studies and $90 \%$ reported within two weeks in the Japonese studies. There was

Serious Hemalologic Events: Two confirmed cases of aplastic anemia and one confirmed case of agranulocytosis were reported in the first 11 years of marketing in Japan, rates were no cases of aplastic anemic and two confirmed cases of agranulocytosis in the US, European, or Japanese development programs. There is inadequate information to assess the
relationship, if any, between dose and duration of treatment

Oligohidrosis and Hyperthermia in Pediatric Patients:

Oligohidrosis, sometimes resulting in heat stroke and hospitalization, is seen in associotion with zonisamide in pediafric patients.

During the pre-approval development program in Japan, one case of oligohidrosis was reported in 403 pediatric potients, an incidence of 1 case per 285 patient-years of exposure. While ment programs, fewer than 100 pediatric patients participated in these tials.

In the first 11 years of marketing in Japan, 38 coses were reported, an estimated reporting rate of about 1 case per ing in the US, 2 cases were reported, an estimated reporting rate of about 12 cases per 10,000 patient-years of exposure. These rotes are underestimates of the true incidence because of in an 18-year-old patient in the US.

Decreased sweating and an elevation in body temperature above normal characterized these cases. Many cases were reporled affer exposure to elevated environmenfal temperatures. cases. There hove been no reported deaths. Pediatric patients appeor to be of an increased risk for
zonisamide-associoted oligohidrosis and hyperthermia.
Patients, especially podiatric potients, treated with Zonegran should be monitored closely for evidence of decreased sweat ing and increased body temperature, especially in warm or hot weather. Caution should be used when zonisamide is prescribed with other drugs that predispose patients to heat carbonic anhydrase inhibitors and drugs with anticholinergic activity.

The practitioner should be aware that the safety and effectiveness of zonisamide in pediatric patients have not been established, and that zonisamide is not approved for use in pediatric patients.

Seizures on Withdrawal: As with other AEDs, abrupt withdraw ONEGRAN in patients with epilepsy may precipitate in or discontinuation of zonisamide should be done gradually.

Teratogenicity: Women of child bearing potential who are given zonisamide should be advised to use effective contraception. Zonisamide was teratogenic in mice, rats, and dogs and of organogenesis. A variely of fetal abnormalities, including cardiovascular defects, and embryo-fetal deaths occurred of maternal plasma levels similar to or lower than therapeutic levels in humans. These findings suggest that the use of ZONEGRAN during pregnancy in humans may present o significant risk to the fetus (see PRECAUTIONS, Pregnoncy subsection). I cannot be said with any confidence, however, that even mild zeizures do not pose some hazards to the developing fetus. tial benefit justities the potential risk to the fetus.

Cognitive/ Neuropsychiatric Adverse Events: Use of ZONEGRAN was frequently associated with central nervous system- oms, including depression and psychosis, 2) psychomotor slowing, difficulty with concentration, and speech or language problems, in particul

In placebo-controlled trials, $2.2 \%$ of patients discontinued ZONEGRAN or were hospitalized for depression compared $0.4 \%$ of placebo patients attempted suicide. Among ail epilep$0.4 \%$ of placebo patients attempted suicide. Among ail epilep-
sy patients treated with ZONEGRAN, $1.4 \%$ were discontinued and $1.0 \%$ were hospitalized because of reported depression or suicide attempts. In placebo-controlled trials, $2.2 \%$ of polients discontinued ZONEGRAN or were hospitalized due to psychosis or psychosis-related symptoms compared to none of the LOacebo patients. Among all epilepsy patients treated with ralized because of reported psychosis or related symptoms.

sychomotor slowing and difficulty with concentration occurred in the first month of treatment and were associated with dose above $300 \mathrm{mg} /$ day. Speech and language problems tended $300 \mathrm{mg} /$ day. Although in most cases these events were of $300 \mathrm{mg} /$ day. Although in most cases these events were of
mild to moderate severity, they at times led to withdrawa from treatment.

Somnolence and fatigue were frequently reported CNS ad verse events during clinical trials with ZONEGRAN. Although in most cases these events were of mild to moderate severity they led to withdrawal from treatment in $0.2 \%$ of the patients enrolled in controlled trials. Somnolence and fatigue tended to occur within the first month of reatment. Somnolence and foPatients should be coutioned about this possibility and specio care should be taken by patients if they drive, operole machin-
ery, or perform any hazardous task.

PRECAUTIONS

General: Somnolence is commonly reported, especially a Neuropsychiatric Adverse Events subsection). Zonisamide is metabolized by the liver and eliminated by the kidneys; caution should therefore be exercised when odministering (see CLNICAL PHARMACOLOGY, Special Populations subsection of full Precribing Information).

Kidney Stones: Among 991 patients treated during the de velopment of ZONEGRAN, 40 patients $(4.0 \%)$ with epilepsy receiving ZONEGRAN developed clinically possible or con phy, etc.), a rate of 34 per 1000 patient-years of exposure symptomatic, and 28 were described as possible kidney stones based on sonographic detection. In nine patients, the diagnosis was confirmed by a passage of a stone or by a definitive
sonographic finding. The rate of occurrence of kidney stones sonographic finding. The rate of occurrence of kidney stones months, 62.6 per 1000 patient-years of exposure between 6 and 12 months, and 24.3 per 1600 patient-years of exposure after 12 months of use. There are no normative sonographic data available for either the general population or patients with epilepsy. The clinical significance of the sonographic finding is unknown. The analyzed stones were composed of calcium or urate salts. In general, increasing fluid intake and urine output can help reduce the risk of stone formation, particularly in whether these measures will reduce the risk of stone formation whether these measures will reduce the

Effect on Renal Function: In several clinical studies, zonisamide was associated with a statistically significant $8 \%$ mean increase from baseline of serum creatinine and blood urea
nitrogen (BUN) compared to essentially no change in the placebo patients. The increase appeared to persist over time but was not progressive; this has been interpreted as an effect on glomerular filtration rate (GFR). There were no episodes of unexplained acute renal failure in clinical development in the US,
Europe, or Japan. The decrease in GFR appeared within the irst 4 weeks of treatment. In a 30-day study, the GFR returned to baseline within 2-3 weeks of drug discontinuation. There is no information about reversibility, affer drug discontinuation, of the effects on GFR after long-term use. ZONEGRAN shouid be discontinued in patients who develop acute renal failure or a concentration. ZONEGRAN should not be used in patients with renal failure (estimated GFR $<50 \mathrm{~mL} / \mathrm{min}$ ) as there has been Sudden Unexplained Death in Epilepsy: During the develop ment of ZONEGRAN, nine sudden unexplained death Occurred among 991 patients with epilepsy receiving ZONE-
GRAN for whom accurate exposure data are available. This represents an incidence of 7.7 deaths per 1000 patient years. Although this rate exceeds that expected in a healthy popula fion, it is within the ronge of estimates for the incidence of
sudden unexplained deaths in patients with refractory epilepsy not receiving ZONEGRAN ranging from 0.5 per 1000 patient-years for the general population of patients with epilepsy, to $2-5$ per 1000 patient-years for patients with refractory epi-
lepsy; higher incidences range from 9-15 per 1000 patientyears among surgical candidates and surgical failures). Some of the deaths could represent seizure related deaths in which the seizure was not observed.

Status Epilepticus: Estimates of the incidence of treatment emergent status epilepticus in ZONEGRAN-trealed patients Nonetheless, in controlled trials, $1.1 \%$ of patients treated with ZONEGRAN had an event labeled as status epilepticus with ZOMpared to none of the patients treated with placebo. Among patients freated with ZONEGRAN across all epilepsy studies controlled and uncontrolled), $1.0 \%$ of patients had an event eported as status epilepticus.

Creatine Phosphokinase (CPK) Elevation and Pancreatitis: In the post-market setting, the
been observed $(<1: 1000)$ :

If patients taking zonisamide develop severe muscle pain d/or weakness, either in the presence or absence of a ing serum CPK and aldolose levels. If elevated, in the absence etc., tapering and/or discontinuance of zonisamide should be considered and appropriate treatment initiated.

Patients taking zonisamide that manifest clinical signs and symptoms of pancreatitis should have pancreatic lipase and amylose leveis monitored. If pancreatitis is evident, in the absence of another obvious cause, tapering and/or discon-
tinuation of zonisamide should be considered and appropriate truation of zonisamic

Information for Patients: Patients should be advised as fol-

1. ZONEGRAN may produce drowsiness, especially at higher doses. Patients should be advised not to drive a car or operate other complex machinery until they hove gained it affects their performance.

Patients should contact their physician immediately if a skin rash develops or seizures worsen.

Patients should contact their physician immediately if they develop signs or symptoms, such as sudden back pain, ab-
dominal pain, and/or blood in the urine, that could indicate a kidney stone. Increasing fluid intoke and urine output may reduce the risk of stone formation, particularly in those with predisposing risk factors for stones.

. Patients should contact their physician immediately if a child with or without a fever.

Because zonisamide can cause hematological complications, patients should contact their physician immediately
if they develop a fever, sore throat, oral ulcers, or easy bruising.

6. As with other AEDs, patients should contact their physician if they intend to become pregnant or are pregnant during if they intend to breast.feed or are breast-feeding an infant. 7. Patients should contact their physician immediately if they develop severe muscle pain and/or weokness.

Laboratory Tests: In several clinical studies, zonisamide was associaled with a mean increase in the concentration of serum creatinine and blood urea nitrogen (BUN) of approximately $8 \%$ over the baseline measurement. Consideration should be
given to monitoring renal function periodically (see PRECAUTIONS, Effect on Renal Function subsection

Zonisamide was associated with an increase in serum alkaline phosphatase. In the randomized, controlled trials, a mean in crease of approximately $7 \%$ over boseline was associated with zonisamide compared to a $3 \%$ mean increase in placebo-treat ed patients. These changes were not statistically sign
The clinical relevance of these changes is unknown.

Drug Interactions: Effects of ZONEGRAN on the pharmacoki netics of other antiepilepsy drugs (AEDs): Zonisamide had no appreciable effect on the steady state plasmo concentration of phenyloin, carbamazepine, or valproate during clinico trials. Zonisamide did not inhibit mixed-function liver oxidase
enzymes (cytochrome P450), as measured in human liver microsomal preparations, in vitro. Zonisamide is not expected to interfere with the metabolism of other drugs that are metabolized by cytochrome P450 isozymes.

Effects of other drugs on ZONEGRAN pharmacokinetics: Drugs that induce liver enzymes increase the merabolism and clearance of zonisamide and decrease its half-lite. The hatelie of on enzyme-inducing AEDs such as phenytoin, carbamazepine or phenobarbital was between $27-38$ hours; the half-lite of zonisamide in patients concurrently on the nonenzyme inducing AED, valproate, was 46 hours. Concurrent medication with to alter serum concentrations of zonisamide.

Interaction with cimetidine: Zonisamide single dose pharma cokinetic parameters were no
four times a day for 12 days).

Carcinogenicity, Mulagenesis, Impairment of Fertility: No evidence of carcinogenicity was found in mice or rats following of up to $80 \mathrm{mg} / \mathrm{kg} /$ day. In mice, this dose is approximatel equivalent to the maximum recommended human dose (MRHD of $400 \mathrm{mg} /$ day on a mg/m $/ \mathrm{m}^{2}$ basis. In rats, this dose is $\mathrm{l}-2$ limes the MRHD on a $\mathrm{mg} / \mathrm{m}^{2}$ basis.

Zonisamide increased mutation frequency in Chinese hamster lung cells in the absence of metabolic activation. Zonisamide was not mutagenic or clastogenic in the Ames test, mouse ymphomo assay, sister chromatid exchange test, and human lymphocyte cytogenetics assay in
row cytogenetics assoy in vivo. Rats treated with zonisamide $(20,60$, or $200 \mathrm{mg} / \mathrm{kg})$ before
mating and during the initial gestation phase showed signs of reproductive toxicity /decreased corpora lutea, implantations, and live fetuses/ at all doses. The low dose in this study is approximately 0.5 times the maximum recommended human
dose (MRHD) on a mg/m² basis. The effect of zonisamide on
human fertility is unknown.

Pregnancy: Pregnancy Category C (see WARNINGS, Teratogenicity subsection): Zonisamide was teratogenic in mice, rats, and dogs and embryolethol in monkeys when administered during the period of organogenesis. Fetal abnormalities or embryo-fetal deaths occurred in these species at zonisamide dosage and maternal plasma levels similar to or lower than therapeutic levels in humans, indicating that use of this drug in pregnancy entails a significant risk to the fetus. A variety of exiernal, visceral, and skeletol malformations was produced in defects were prominent in both rats and dogs.

Following administration of zonisamide 110,30 , or $60 \mathrm{mg} /$ $\mathrm{kg} /$ day) to pregnant dogs during organogenesis, increased 
septal defects, cardiomegaly, various valvular and arteria anomalies) were found at doses of $30 \mathrm{mg} / \mathrm{kg} /$ day or greater. The low effect dose for malformations produced peak maternal plasma zonisamide levels $(25 \mu \mathrm{g} / \mathrm{mL})$ about 0.5 times the highest plasma levels measured in patients receiving the maximum recommended human dose (MRHDI of $\mathrm{mg} /$ day. In dogs, cardiovascular malkormations were found which was ossolis which was associated with maternal plasma levels $44 \mathrm{jg} / \mathrm{mL}$ opproximately equal to the highest levels measured in human

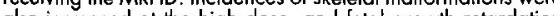
also increased at the high dose, and fetal growth retardation and increased requencies of skelelal varianions were seen a all doses in this theqdy The low ske produced maternal plasma levels (12 $\mathrm{\mu g} / \mathrm{mL})$ obout 0.25 times the highest human levels. In cynomolgus monkeys, administration of zonisamide (10 or $20 \mathrm{mg} / \mathrm{kg} /$ day) to pregnant animals during organogenesis resulted in embryo were due to malformations cannot be ruled out. The lowest embryolethal dose in monkeys was associated with peak maternal plasma zonisamide levels $15 \mathrm{\mu g} / \mathrm{mL}$ ap with peak maternal plasma zonisamide leveis $(5 \mu \mathrm{gg} / \mathrm{mL}$ ) ap at the MRHD.

In a mouse embryo-fetal development study, treatment of preg nant animals with zonisamide $(125,250$, or $500 \mathrm{mg} / \mathrm{kg} /$ day during the period of organogenesis resulted in increased incidences of fetal malformations /skeletal and/or craniofacia defects) at all doses tested. The low dose in this study is op proximately 1.5 times the MRHD on a $\mathrm{mg} / \mathrm{m}^{2}$ basis. In rats, in creased frequencies of malformations /cardiovascular defects and variations (persistent cords of thymic tissue, decreased skeletal ossificationl were observed omong the offspring of dams treated with zonisamide $(20,60$, or $200 \mathrm{mg} / \mathrm{kg} /$ day $)$ approximately 0.5 times the MRHD on a mg $/ \mathrm{m}^{2}$ basis.

Perinatal death was increased among the offspring of rats treated with zonisamide $(10,30$, or $60 \mathrm{mg} / \mathrm{kg} / \mathrm{day})$ from the latter part of gestation up to weaning at the high cose, o approximately 1.4 times the MRHD on a $\mathrm{mg} / \mathrm{m}^{2}$ basis. The $\mathrm{n}$ effect level of $30 \mathrm{mg} / \mathrm{kg} / \mathrm{day}$ is opproximately 0.7 times the RHD on a $\mathrm{mg} / \mathrm{m}^{2}$ bas

There are no adequate and well-controlled studies in pregnant wo potential benefit justifies the potential risk to the fetus.

Labor and Delivery: The effect of ZONEGRAN on labor and delivery in humans is not known.

Use in Nursing Mothers: It is not known whether zonisamide is excreted in human milk. Because many drugs are excreted in human milk and because of the potential for serious adverse reactions in nursing infants from zonisamide, a decision should be made whether to discontinue nursing or to discontinue drug taking into account the importance of the drug to the mother.
ZONIEGRAN should be used in nursing mothers only if the benefits outweigh the risks.

Pediatric Use: The safety and effectiveness of ZONEGRAN in children under age 16 have not been established. Cases of oligohidrosis and hyperpyrexia have been reported (see Patients subsection)

Geriatric Use: Single dose pharmacokinetic parameters are similar in elderly and young healthy volunteers (see CUNIPrescribing Information). Clinical studies of zonisamide did Prescribing Information). Clinical studies of zonisamide did not include sulficient numbers of subjects aged 65 and over to determine whether they respond differently from younger subjects. Other reported clinical experience has not identified differences in responses belween the elderly and younger potients. In general, dose selection for an elderly patient should be coutious, usucily starting at the low end of the dosing range, reflecting the greater frequency of decreased hepatic, renal,
or cardiac function, and of concomitant disease or other drug theropy.

\section{ADVERSE REACTIONS}

The most commonly observed adverse events associated with the use of ZONEGRAN in controlled clinical trials that were not seen at an equivalent frequency among placebo-treated patients were somnolence, anorexio, dizziness, headache, patients were somnolence, anorex
nausea, and ogitation/irritability.

In controlled clinical trials, $12 \%$ of patients receiving ZONE GRAN as adjunctive therapy discontinued due to an adverse event compored to $6 \%$ receiving placebo. Approximately $21 \%$ of the 1,336 patients with epilepsy who received ZONEGRAN
in clinical studies discontinued treatment because of an adverse event. The adverse events most commonly associated with discontinuation were somnolence, fatigue and/or ataxio $16 \%$, anorexia $(3 \%)$, difficulty concentrating $(2 \%)$ difficulty with memory, mental slowing, nausea/vomiting $(2 \%)$, and weigh loss (1\%). Many of these adverse events were dose-related (see

Adverse Event Incidence in Controlled Clinical Trials: Table 3 lists treatmentemergent adverse events that occurred in at leas $2 \%$ of patients treated with ZONEGRAN in controlled clinica trials that were numerically more common in the ZONEGRAN group In these studies, either ZONEGRAN or placebo wos
added to the patient's current AED therapy. Adverse events added to the patient's current AED therapy.
were usually mild or moderate in intensity.

The prescriber should be aware that these figures, obtained when ZONEGRAN was added to concurrent AED therapy, cannot be used to predict the frequency of adverse events in the course of usual medical practice when patient char acteristics and other factors may differ from those prevailing during clinical studies. Similarly, the cited frequencies canno be directly compared with figures obtained from other clinical investigations involving different treatments, uses, or investigators. An inspection of these trequencies, however, does provide the prescriber with one basis by which to estimate the relative contribution of drug and non-drug factors to the adverse even
incidences in the population studied.

Table 3. Incidence $(\%)$ of Treotment-Emergent Adverse Events

curred in at least $2 \%$ of ZONEGRAN-treated patients and occurred more frequenty in ZONEGRAN-treated and occurred more frequently in

ZONEGRAN ( $n=269$ ) PLACEBO $(n=230)$

BODY AS A WHOLE Headache $(10 \% / 8 \%$, Abdominal Pain $6 \% / 3 \%$, Flu Syndrome $4 \%$, Diorrea $15 \% / 2 \%$ Anorexia $3 \% / 1 \%)$, Constipation (2\%/ $1 \%$, Dry Mouth $(2 \% / 1 \%)$ HeMsiaTOLOGIS AND LYMPHATIC Ecchymosis $(2 \% / \%)$ METABOLIC TOLOGIS AND LYMPHATIC Ecchymosis $(2 \% / 1 \%)$ METABOLIC
AND NUTRITIONAL Weight Loss $(3 \% / 2 \%)$ NERVOUS SYSIEM Dizziness $(13 \% / 7 \%)$, Ataxia $(6 \% / 1 \%)$, Nystagmus $(4 \% / 2 \%)$ Paresthesia $(4 \% / 1 \%)$, NEUROPSYCHIATRIC AND COCNITIVE DYSFUNCTION-ALTERED COGNITIVE FUNCTION Confusion $(6 \% / 3 \%)$, Difficulty Concentrating $(6 \% / 2 \%)$, Difficulty with Memory $(6 \% / 2 \%)$, Mental Slowing $(4 \% / 2 \%)$ NEUROPSYCHIATRIC AND COGNITIVE DYSFUNCTION-BEHAVIORAL ABNOR-

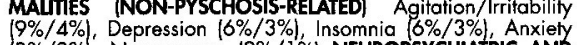
$(9 \% / 4 \%)$. Depression $(6 \% / 3 \%)$, Insomnia $(6 \% / 3 \%)$, Anxiely COGNITIVE DYSFUNCTION-BEHAVIORAL ABNORMALITES (PYSCHOSIS-RELATED) Schizophrenic/Schizophreniform Behavior $(2 \% / 0 \%)$ NEUROPSYCHIATRIC AND COGNITIVE DYSFUNCTION-CNS DEPRESSION Somnolence $(17 \% / 7 \%$ ) Fatigue $(8 \% / 6 \%)$, Tiredness $(7 \% / 5 \%)$ NEUROPSYCHIATRIC AND COGNITIVE DYSFUNCTION-SPEECH AND LANGUAGE
ABNORMALITIES Speech Abnormalities $(5 \% / 2 \%)$ Difficulties in Verbal Expression $(2 \% /<1 \%)$ RESPIRATORY Rhinitis (2\%) $1 \%)$ SKIN AND APPENDAGES Rash $(3 \% / 2 \%)$ SPECIAL SENSES Diplopia $(6 \% / 3 \%)$, Taste Perversion $(2 \% / 0 \%)$

Other Adverse Events Observed During Clinical Trials: ZONE GRAN has been administered to 1,598 individuals during all clinical trials, only some of which were placebo-controlled. clinical trials, only some of which were placebo-controled.
During these trials, all events were recorded by the investigaDuring these trials, all events were recorded by the investiga-
tors using their own terms. To provide a useful estimate of the tors using their own terms. To provide a useful estimate of the
proportion of individuals having adverse events, similar events proportion of individuals having adverse events, similar events egories using a modified COSTART dictionary. The frequencies egories using a modified COSTART dictionary. The frequencies ZONEGRAN who experienced an event on at least one occasion. All events are included except those already lisfed in the sion. All events are included except those already lisfed in the trivial events, those too general to be informative, and those not reasonably associated with ZONEGRAN.

Events are further classified within each category and listed in order of decreasing frequency as follows: frequent occurring in at least 1:100 patient; infrequent occurring in 1:100 to 1 : 1000 patients; rare occurring in fewer than 1:1000 patients.

Body as a Whole: Frequent: Accidental injury, asthenia. Infre quent: Chest pain, flank pain, malaise, allergic reaction, face edema, neck rigidity. Rare: Lupus erythematosus.

Cardiovascular: Infrequent: Palpitation, tachycardia, vascular insufficiency, hypotension, hypertension, thrombophlebitis, pulmonary embolus, ventricular extrasystoles.

Digestive: Frequent: Vomiting. Infrequent: Flatulence, gingivitis, gum hyperplasia, gastritis, gastroenteritis, stomatitis, chole-
lithiasis, glossitis, melena, rectal hemorrhage, ulcerative stomatitis, gastro-duodenal ulcer, dysphagia, gum hemorrhage. Rare: Cholangitis, hematemesis, cholecystitis, cholestatic jaundice, colitis, duodenitis, esophagitis, fecal incontinence,
mouth ulceration.

Hemotologic and Lymphatic: Infrequent: Leukopenia, anemia, immunodeliciency, lymphadenopathy. Rare: thrombocytope nia, microcytic anemia, petechia.

Metabolic and Nutritional: Infrequent: Peripheral edemo weight gain, edema, thirst, dehydration. Rare: Hypoglyce-
mia, hyponatremia, lactic dehydrogenase increased, SGOT

increased, SGPT increased.

Musculoskeletal: Infrequent: Leg cramps, myalgia, myasthenia, arthralgia, arthritis.

Nervous System: Frequent: Tremor, convulsion, abnormal gait, hyperesthesia, incoordination. Infrequent: Hypertonia, twitch ing, abnormal dreams, vertigo, libido decreased, neuropathy, hyperkinesia, movement disorder, dysarthria, cerebrovascula accident, hypotonia, peripheral neuritis, parathesia, reflexe increased. Rare: Circumoral paresthesia, dyskinesia, dystonia encephalopathy, facial paralysis, hypokinesia, hyperesthesia myoclonus, oculogyric crisis.

Behovioral Abnormalities - Non-Psychosis-Reloted: Infrequent: Euphoria.

Respiratory: Frequent: Pharyngitis, cough increased. Infre quent: Dyspnea. Rare: Apnea, hemophysis.

Skin and Appendages: Frequent: Pruritus. Infrequent: Maculopapular rash, acne, alopecia, dry skin, sweating, eczema, urticaria, hirsutism, pustular rash, vesiculabullous rosh.

Special Senses: Frequent: Amblyopia, tinnitus. Infrequent: Con junctivitis, parosmia, deafness, visual field defect, glaucoma Rare: Photophobia, iritis.

Urogenital: Infrequent: Urinary frequency, dysuria, urinary incontinence, hematuria, impotence, urinary retention, urinary urgency, amenorrhea, polyuria, nocturia. Rare: Albuminuria, enuresis, bladder pain, bladder calculus, gynecomastia, mastitis, menorrhagia.

\title{
élan
}

\author{
Distributed by: \\ Elan Biopharmaceuticols a business unit \\ of Elan Pharmaceuticals, Inc. \\ a member of the Elan Group, San Diego, CA 9212 \\ ZONEGRAN is a trademark licensed exclusively to \\ Elan Pharmaceuticals, ine. \\ (c) 2000, 2003 Elan Pharmaceuticals, Inc.
}

